\title{
Editorial
}

\section{Solar Thermal Engineering}

\author{
Alibakhsh Kasaeian, ${ }^{1}$ Michel Feidt, ${ }^{2}$ Stoian Petrescu, ${ }^{3}$ and Adel Mellit ${ }^{4}$ \\ ${ }^{1}$ Department of Renewable Energies, Faculty of New Sciences \& Technologies, University of Tehran, Tehran, Iran \\ ${ }^{2}$ Department of Physics and Mechanics, Faculty of Sciences and Technology, University Henri Poincaré, Nancy, France \\ ${ }^{3}$ Department of Engineering Thermodynamics, Engines, Thermal and Refrigeration Equipments, University Politehnica of Bucharest, \\ Bucharest, Romania \\ ${ }^{4}$ Renewable Energy Laboratory, Jijel University, 1800 Jijel, Algeria
}

Correspondence should be addressed to Alibakhsh Kasaeian; akasa@ut.ac.ir

Received 14 August 2017; Accepted 14 August 2017; Published 2 November 2017

Copyright (C) 2017 Alibakhsh Kasaeian et al. This is an open access article distributed under the Creative Commons Attribution License, which permits unrestricted use, distribution, and reproduction in any medium, provided the original work is properly cited.

The increasing demands to energy, from one side, and the global warming crisis of the world, from other side, are the reasons for developing renewable energies [1]. Among all resources of renewable energies, solar energy is the unlimited resource which can be exploited all over the world. The prices for solar generation technologies continue to rapidly decrease; so that, in some cases, the cost is competitive with the fossil fuel costs [2]. The thermal conversion of solar energy is possible by different collectors including flat and concentrating collectors. For the purpose of reaching largescale energy conversion in both forms of electricity and thermal, the usage of different solar concentrating collectors would be a favorite selection [1]. Besides the application of solar flat and concentrating collectors, other kinds of energy conversion units have been focused by different researchers. For achieving wind and rotating turbines, solar chimneys would be a preferred option in the windless zones [3]. Also, for the purpose of supplying potable water, the solar stills have been developed in different types and designs [4].

In the recent years, in case of the application of solar thermal systems, the usage of special materials has been paid attention for increasing the efficiency. For instance, using of nanofluids has been the subject of research by many researchers [5]. Nanofluids are capable to enhance the heat transfer coefficient of the working fluids, which are circulating through the absorber tubes of the solar thermal units. Also, the phase change materials (PCMs) are another materials which have found a special situation in the solar thermal systems. PCMs can store/release a large amount of heat during melting/solidification or gasification/liquefaction processes. Since the phase-transition enthalpy of PCMs is usually much higher than sensible heat, latent heat storage has much higher storage density than sensible heat storage [6]. So, this case will be another potential for the future studies in the field of solar thermal energy.

Regarding the importance of solar energy as the main sustainable resource among all renewable resources, it was interesting to gather the research findings of this subject in a special issue. The issue covers all new research articles about solar radiation and solar thermal energy systems. The aim was focused on the thermal conversion aspect of solar energy. So, the conversion systems including flat collecting and concentrating systems were gathered in this issue. Besides the technical issues related to solar thermal energy, the economic and environmental subjects were of interest for review. So, the topics including solar radiation, potential and feasibility study, flat and evacuated tube collectors, trough and Fresnel collectors, solar Stirling systems, heliostat fields, solar chimney, solar desalination, nanofluid in solar thermal systems, green buildings, passive solar systems, solar biomimetic systems, optimization in solar thermal systems, economic aspects of solar power plants, and solar $\mathrm{CHP}$ were announced for this special issue. Here, the published papers are placed in the categories of flat and evacuated tube collectors, trough and Fresnel collectors, solar chimney, green buildings, and photovoltaic thermal systems. 
In case of flat collectors, the authors investigated a smallscale solar thermal collector. The absorber was coated with a selective coating, and the study was carried out for a lowpressure environment to increase the performance. Then, a numerical model was developed to predict the performance of the collector plate. In another study, the researchers conducted a detailed modelling of flat plate solar collectors with vacuum glazing, based on the combined external and internal energy balance of the absorber. In this special issue, some authors report the application of phase change materials for a solar chimney, and the storage capability and the night ventilation performance of the system have been assessed. Regarding solar trough collector, a paper is presented for elliptical cavity tube receivers in a parabolic trough solar collector. The authors have designed and optimized the cavity receivers and concluded that the focal distance has a negative relation with the cavity open length, whereas the concentration ratio has a positive relation with the cavity open length. Another paper in this special issue is allocated to a watercooled PVT (photovoltaic thermal) unit. The authors have demonstrated that the use of maximum power point tracking has a much better function than the fixed optimized.

In the field of energy in buildings and space heating, two papers are reported in this special issue. One is specified for a nearly zero-energy building, which has been done in China as a case study. A solar heating and cooling system including a $35.17 \mathrm{~kW}$ cooling absorption chiller, an evacuated tube solar collector, two hot-water storage tanks, two cold-water storage tanks, and a $281 \mathrm{~kW}$ cooling tower has been designed and built by the researchers. Another study talks about the effects of ambient conditions on the performance of a direct-expansion solar-assisted heat pump. In this paper, by applying bare plate evaporators for space heating, the effects of ambient temperature, solar irradiation, and relative humidity on the system performance are assessed.

We hope that many researchers from universities, research centers, and industry read the papers of this special issue. Also, it is our pleasure to present this special issue in the field of solar thermal energy; so we hope that the readers find this special issue helpful and effective.

\section{Alibakhsh Kasaeian Michel Feidt Stoian Petrescu Adel Mellit}

[4] H. Panchal and I. Mohan, "Various methods applied to solar still for enhancement of distillate output," Desalination, vol. 415, pp. 76-89, 2017.

[5] O. Mahian, A. Kianifar, S. A. Kalogirou, I. Pop, and S. Wonwises, "A review of the applications of nanofluids in solar energy," International Journal of Heat and Mass Transfer, vol. 57, no. 2, pp. 582-594, 2013.

[6] Y. Tian and C. Y. Zhao, "A review of solar collectors and thermal energy storage in solar thermal applications," Applied Energy, vol. 104, pp. 538-553, 2013.

\section{References}

[1] F. Wang, Z. Cheng, J. Tan, Y. Yuan, Y. Shuai, and L. Liu, "Progress in concentrated solar power technology with parabolic trough collector system: a comprehensive review," Renewable and Sustainable Energy Reviews, vol. 79, pp. 1314-1328, 2017.

[2] W. Herche, "Solar energy strategies in the U.S. utility market," Renewable and Sustainable Energy Reviews, vol. 77, pp. 590-595, 2017.

[3] M. Ghalamchi, A. B. Kasaeian, M. Ghalamchi, and A. Hajiseyed Mirzahosseini, "An experimental study on the thermal performance of a solar chimney with different dimensional parameters," Renewable Energy, vol. 91, pp. 477-483, 2016. 

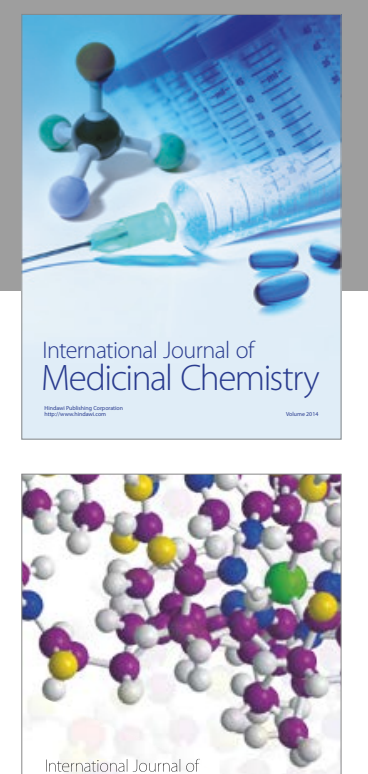

Carbohydrate Chemistry

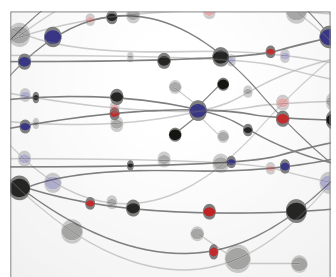

The Scientific World Journal
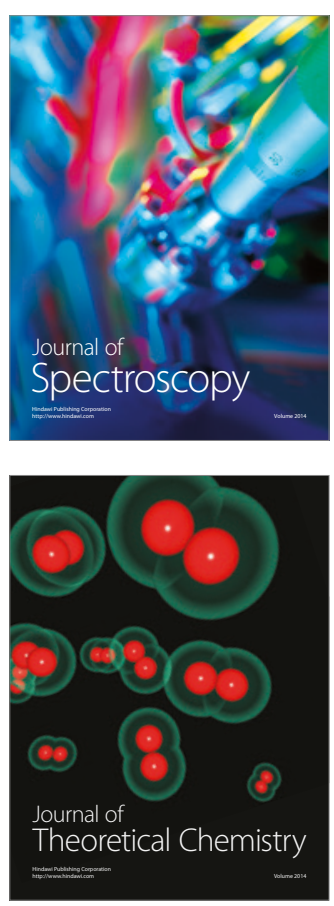
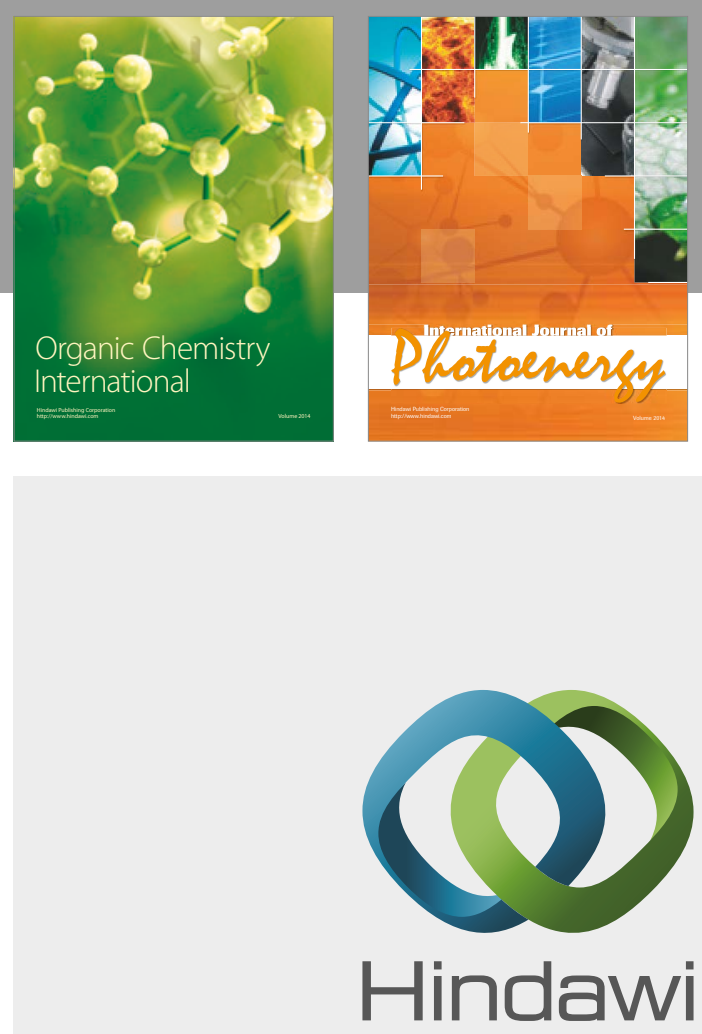

Submit your manuscripts at

https://www.hindawi.com

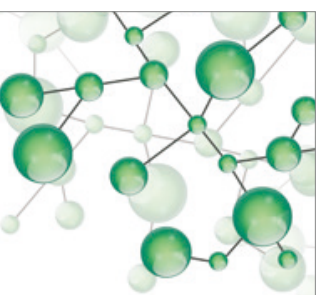

International Journal of

Inorganic Chemistry

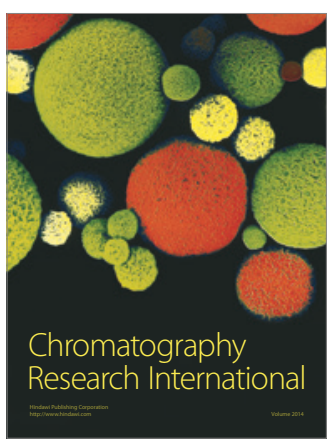

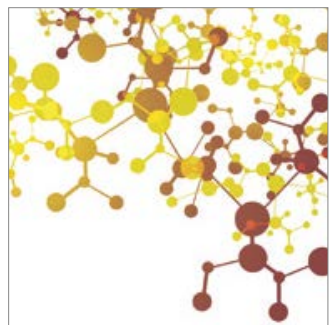

Applied Chemistry
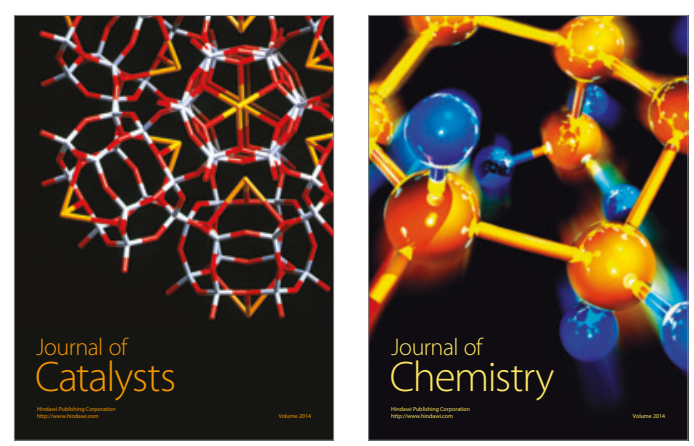
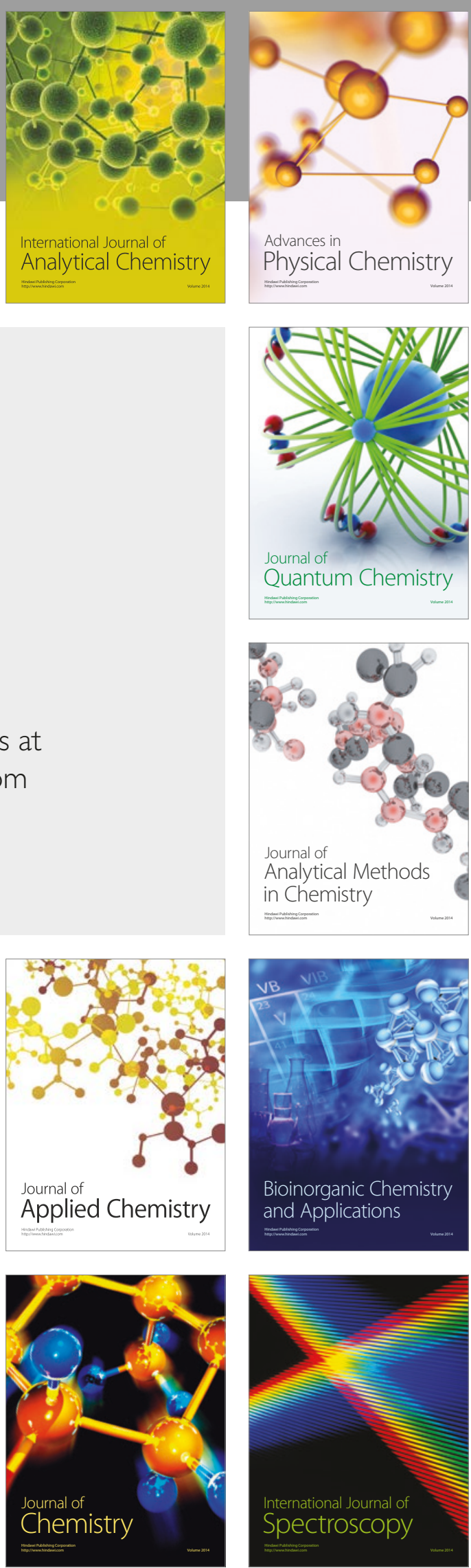